\title{
GAS CHROMATOGRAPHY-MASS SPECTROMETRY ANALYSIS OF METHANOL EXTRACT OF ZANTHOXYLUM RHETSA DC. FRUITS
}

\author{
KULADIP GURAV, VARSHA JADHAV (RATHOD)*
}

Department of Botany, Shivaji University Kolhapur, Maharashtra, India. Email: vsrathod.botany@gmail.com

Received: 30 July 2018, Revised and Accepted: 30 July 2018

ABSTRACT

Objective: The aim was to investigate important bioactive compounds, biological activities, and medicinal importance of Zanthoxylum rhetsa fruits.

Methods: The present work was carried out by gas chromatography-mass spectrometry (GC-MS) method for the identification of different compounds.

Result: The methanolic extract of fruits showed 32 chemical compounds which are identified through GC-MS analysis. Among them, some of the compound names and percentage values are as follows: 2-propanone, 1,3-dihydroxy (48.9\%), 4H-pyran-4-one,2,3-dihydro-3,5-dihydroxy-6-methyl (33.7\%), 2-furancarboxaldehyde, 5-[hydroxymethyl] (50.2\%), 1-Heptatriacontanol (34.4\%), 9,12-octadecadienoic acid (zz)- (48.6\%), cholestan3-ol,2-methylene, [3 $\beta, 5 \alpha]$ (75.0\%), 4H-pyran-4-one, 2,3-dihydro-3,5-dihydroxy-6-methyl (90.8), 2-furancarboxaldehyde, 5-[hydroxymethyl] (92.0\%), hydroquinone (64.9\%), n-hexadecanoic acid (37.5\%), octadecanoic acid (28.2\%), 9,12,15, octadecatrienoic acid, 2-[(trimethylsiyl]oxy]-1[(trimethylsiyl] oxy]methyl] ethyl ester, [zzz] (22.6\%), 9-hexadecanoic acid (10.3\%), digitoxin (18.8\%), 8,11,14-eicosatrienoic acid methyl ester, [zzz] (25.5\%), and oleic acid (16.5\%). Most of the identified compounds in the crude methanolic extracts exhibit some bioactivities, namely anticancer, antiinflammatory, antimicrobial, hepatoprotective, antioxidant, hypocholesterolemic, nematicide, pesticide, anti-androgenic flavor, hemolytic, 5-alphareductase inhibitor, insectifuge, antiarthritic, anti-coronary, cardiovascular, anti-breast cancer, aromatic, and insectifuge. On the basis of the above investigation, the fruits can be recommended as a treasure of bioactive compounds and it plays a promising role in herbal medicine.

Conclusion: The present study reveals that fruits of $Z$. rhetsa contain various bioactive compounds. Digitoxin is recorded in the ripened fruit of Z. rhetsa and it shows the anticancerous and cardiac arrest properties. Hence, in future, this plant will play a promising role in curing cancer.

Keywords: Zanthoxylum rhetsa fruits, Gas chromatography-mass spectrometry analysis, Bioactive components.

(C) 2018 The Authors. Published by Innovare Academic Sciences Pvt Ltd. This is an open access article under the CC BY license (http://creativecommons. org/licenses/by/4. 0/) DOI: http://dx.doi.org/10.22159/ajpcr.2018.v11i12.26821

\section{INTRODUCTION}

Medicinal plants play an important role in human life. Most of the natural products produced by plants are benefiting for humankind, as a food, cosmetics, clothing, building material, tools, and medicines. Most of the medicinal plants are the important source for the discovery of new drugs and drug development. Most of the plant drugs are the secondary metabolites, and it is very much useful for mankind [1]. According to the World Health Organization (WHO), $70-80 \%$ of the developing country populations are using traditional plant products as an alternative or complementary medicine [2]. The genus Zanthoxylum is belonged to family Rutaceae and economically important because of their alimentary, industrial, and medicinal applications [3,4]. Zanthoxylum comprises about 549 species distributed worldwide mainly in tropical and temperate regions [5]. The genus Zanthoxylum has enormous importance due to its ethnobotanics, phytochemistry, and biological activity, and it is a promising source of various secondary metabolites. Zanthoxylum rhetsa is a medium-sized, deciduous, aromatic, and medicinal tree commonly known as tirphal or chirphal in adjoining area of Kolhapur district. The fruits are aromatic and possess properties such as a stimulant, astringent, stomachache, and digestive. It is also prescribed for urinary diseases, dyspepsia, and diarrhea [6]. This species has potential pharmaceutical applications include cancer treatment, antioxidant, anticoagulant, and antibacterial agents. At the industrial level, species have been shown to contain high amounts of linalool [7], a compound used commercially as a precursor to Vitamin E production, for making soaps, detergents, and insecticides. Screening of the bioactive constituents leads to the development of new novel drugs for curing various maladies [8].

In the present investigation, we have reported important bioactive compounds such as digitoxin, 9 12-octadecadienoic acid (zz)-, 1-heptatriacontanol, n-hexadecanoic acid, and octadecanoic acid. Hence, the present work can act as an activated vein for tribal people for their economic and medicinal purpose. Considering the importance of these compounds in medicine, the present study is necessary.

\section{MATERIALS AND METHODS}

Collection of plant material

Plants materials were collected in flowering and fruiting stages in JuneFebruary from adjoining areas of Kolhapur district. The specimens were identified by utilizing taxonomic keys and regional floras and authenticated at Angiosperm Taxonomy laboratory, Shivaji University, Kolhapur. The herbariums were prepared by the standardized method and deposited at the Shivaji University Herbarium (SUK) (Collection No.-KDG4).

\section{Preparation of plant extracts}

The collected plant materials were transferred immediately to the laboratory and cleaned with water. Selected plant parts were separately shade dried until weight has been constant [9]. The powder for further analysis was prepared using grinder [10], then passed through $40 \mathrm{~mm}$ mesh, and stored in a clean container for further use [11]. The extraction was done with the help of methanol using the Soxhlet apparatus [12] for $18 \mathrm{~h}$ at a temperature not exceeding the boiling point of the respective solvent $[13,14]$. The obtained extracts were filtered using Whatman No. 1 filter paper, concentrated using an evaporator at $40^{\circ} \mathrm{C}$ [15], and stored the residual extracts in the refrigerator at $4{ }^{\circ} \mathrm{C}$ in small and sterile amber color glass bottles [16].

Gas chromatography-mass spectrometry (GC-MS) analysis GC-MS analysis was carried out by Hema et al. [17] method. Its model name QP 2010 series, Shimadzu, Tokyo, Japan, has well equipped 
with a VF-5 m fused silica capillary column of $60 \mathrm{~m}$ length, $0.25 \mathrm{~mm}$ diameter, and $0.25 \mathrm{~mm}$ film thickness [18], and it was used during GCMS analysis. $2 \mathrm{~mL}$ of respective diluted samples was manually injected in the splitless mode, with split ratio of 1:40 and with mass scan of 50-600 am. Its linear velocity, pressure and purge flow was $0.289 \mathrm{~m} / \mathrm{s}$, $173.3 \mathrm{k} \mathrm{Pa}$ and $3.0 \mathrm{~mL} / \mathrm{min}$ respectively. For GC-MS detection [GC2010], an electron ionization system with ionization energy of $70 \mathrm{eV}$ was used. Helium gas (99.99\%) was used as a carrier gas at a constant flow rate - total flow: $16.3 \mathrm{~mL} / \mathrm{min}$ and column flow: $1.21 \mathrm{~mL} / \mathrm{min}$. Injector and mass transfer line temperature were set at $200^{\circ} \mathrm{C}$ and $240^{\circ} \mathrm{C}$, respectively. The oven temperature was programmed (column oven temperature: $100^{\circ} \mathrm{C}$ and injection temperature: $270^{\circ} \mathrm{C}$ ) from $70^{\circ} \mathrm{C}$ to $220^{\circ} \mathrm{C}$ at $283.15 / \mathrm{min}$, held isothermal for $60 \mathrm{~s}$, and finally raised to $300^{\circ} \mathrm{C}$ at $10^{\circ} \mathrm{C} / \mathrm{min} .2 \mathrm{~mL}$ of respective diluted samples was manually injected in the splitless mode, with split ratio of 1:40 and with mass scan of 50-600 am. Total running time of GC-MS for mature fruit sample was recorded between 4.39 and $34.36 \mathrm{~min}$, and for ripened fruit, it was from 8.18 to $34.36 \mathrm{~min}$. The relative percentage amount of each component was calculated by comparing its average peak area to the total areas, software adapted to handle mass spectra, and chromatograms was a turbomass. The relative percentage of each extract constituents was expressed as a percentage with peak area normalization. Identification of components and interpretation on mass spectrum of GC-MS were done using the database of the National Institute of Standard and Technology NIST-08 LIB and WILEY-8 LIB. Library. The mass spectrum of the unknown component was compared with the spectrum of the known components stored in the NIST library. The name, molecular weight, and structure of the components of the test material were ascertained [19].

\section{RESULTS}

\section{GC-MS of methanol extracts of $Z$. rhetsa mature fruit}

In the present investigation, the fruit powder of Z. rhetsa was extracted by the methanolic solvent, and it showed pale yellow-colored oil. GC-MS analysis of the methanol extract of the mature fruit of $Z$. rhetsa showed fifteen peaks. The constituents are depicted in Figs. 1-8 and Table 1 with their retention time (RT), molecular formula, molecular weight, area, probability percentage, and important activity. Higher probability percentage was recorded in 2-furancarboxaldehyde, 5-[hydroxymethyl] (50.2\%), 2-propanone, 1, 3-dihydroxy (48.9\%), 9, 12-octadecadienoic acid (zz) (48.6\%), tricyclo [20.8.0.0 [7,16] triacontane, 1 [22], 7 [16] diepoxy (38.3\%) and 1-heptatriacontanol (34.4\%), respectively, while the remaining of the probability range lies from $33.7 \%$ to $8.59 \%$.

Table 1: The compounds identified from the methanol extract of the mature fruit of Zanthoxylum rhetsa by gas chromatography-mass spectrometry (GC-MS)

\begin{tabular}{|c|c|c|c|c|c|c|}
\hline R.T. & Name of compound & Area & Probability & Activity & MF & MW \\
\hline 4.39 & 2-Propanone, 1,3-dihdroxy & 12481 & 48.9 & - & $\mathrm{C}_{3} \mathrm{H}_{6} \mathrm{O}_{3}$ & 90 \\
\hline 4.58 & 1,3-Diethoxy-2-methylenepropane & 10417 & 18.3 & - & $\mathrm{C}_{8}^{3} \mathrm{H}_{16}^{6} \mathrm{O}_{2}^{3}$ & 144 \\
\hline 7.02 & 1H-Azonine, octahydro-1-nitroso & 25478 & 14.9 & Antibacterial[20] & $\mathrm{C}_{8}^{8} \mathrm{H}_{16}^{10} \mathrm{~N}_{2}^{2} \mathrm{O}$ & 156 \\
\hline 8.17 & $\begin{array}{l}\text { 4H-Pyran-4-one, } \\
\text { 2,3-dihydro -3,5-dihydroxy -6-methyl }\end{array}$ & 8268 & 33.7 & Aroma compound [21] & $\mathrm{C}_{6}^{8} \mathrm{H}^{16} \mathrm{O}_{4}$ & 144 \\
\hline 9.70 & $\begin{array}{l}\text { 2-Furancarboxaldehyde, } \\
\text { 5-[hydroxymethyl] }\end{array}$ & 29220 & 50.2 & $\begin{array}{l}\text { Antimicrobial, } \\
\text { preservative [22] }\end{array}$ & $\mathrm{C}_{6} \mathrm{H}_{6} \mathrm{O}_{3}$ & 126 \\
\hline 24.32 & 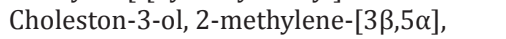 & 38425 & 9.78 & Antioxidant[23] & $\mathrm{C}_{28} \mathrm{H}_{48} \mathrm{O}$ & 400 \\
\hline 24.60 & Oleic acid & 32354 & 22.7 & $\begin{array}{l}\text { Cardiovascular effects, } \\
\text { effects on tumor tissue [24] }\end{array}$ & $\mathrm{C}_{18} \mathrm{H}_{34} \mathrm{O}_{2}$ & 282 \\
\hline 25.86 & $\begin{array}{l}\text { Card-20 (22) enolide, 3,5,14,19-] } \\
\text { tetrahydroxy-, }[3 \beta, 5 \alpha]\end{array}$ & 22824 & 8.59 & - & $\mathrm{C}_{23} \mathrm{H}_{34} \mathrm{O}_{6}$ & 406 \\
\hline 26.95 & $\begin{array}{l}\text { Tricyclo[20.8.0.0[7,16]triacontane, } \\
1[22], 7[16] \text {-diepoxy }\end{array}$ & 26203 & 38.3 & - & $\mathrm{C}_{30} \mathrm{H}_{52} \mathrm{O}_{2}$ & 444 \\
\hline 28.61 & 1-Heptatriacontanol & 45203 & 34.4 & $\begin{array}{l}\text { Antioxidant, anticancer, } \\
\text { anti-inflammatory, and sex } \\
\text { hormone activity [25] }\end{array}$ & $\mathrm{C}_{37} \mathrm{H}_{76} \mathrm{O}$ & 536 \\
\hline 28.81 & 9 12-octadecadienoic acid (z z)- & 43880 & 48.6 & $\begin{array}{l}\text { Anti-inflammatory } \\
\text { Hypocholesterolemic Cancer } \\
\text { preventive, } \\
\text { Hepatoprotective, } \\
\text { Nematicide Insectifuge, } \\
\text { Antihistaminic, } \\
\text { Antieczemic, Antiacne, } \\
\text { 5-Alpha reductase } \\
\text { inhibitor Antiandrogenic, } \\
\text { Antiarthritic, Anticoronary, } \\
\text { Insectifuge [26] }\end{array}$ & $\mathrm{C}_{16} \mathrm{H}_{32} \mathrm{O}_{2}$ & 280 \\
\hline 30.76 & $\begin{array}{l}\text { 9,12,15, Octadecatrienoic acid } \\
\text { 2-[(trimethylsiyl }] \text { oxy }]-1-[(\text { trimethylsiyl }] \\
\text { oxy] methyl }] \text { ethyl ester,[ZZZ] }\end{array}$ & 42383 & 30.8 & Antimicrobial [27] & $\mathrm{C}_{28} \mathrm{H}_{40} \mathrm{O}_{4}$ & 440 \\
\hline 31.10 & $6 \beta$-Hydroxyfluoxymesterone & 42849 & 17.4 & - & $\mathrm{C}_{20} \mathrm{H}_{29} \mathrm{FO}_{4}$ & 352 \\
\hline
\end{tabular}

M.F: Molecular formula, M.W: Molecular weight. Probability is in percentage (\%) 


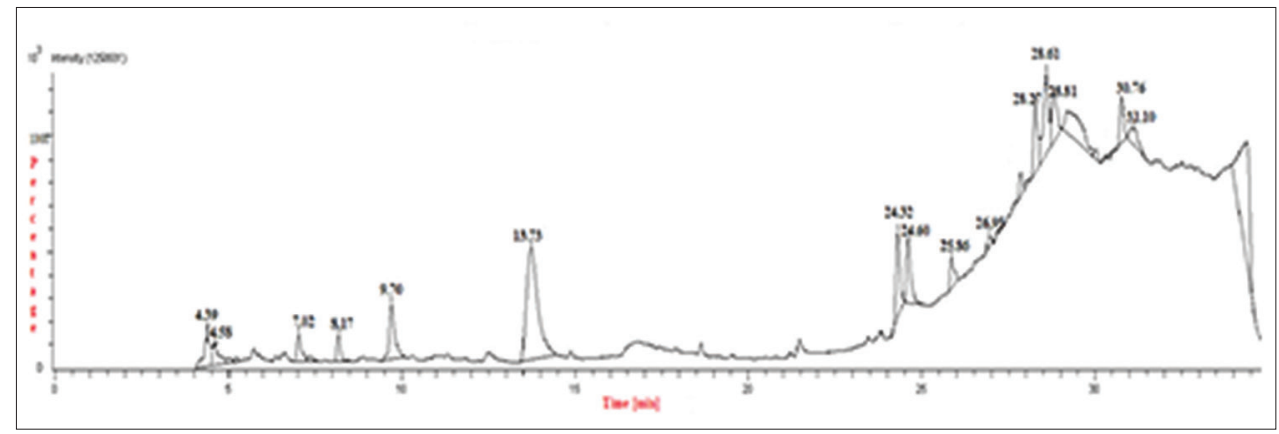

Fig. 1: Gas chromatography-mass spectrometry chromatogram of the methanol extract of Zanthoxylum rhetsa mature fruit

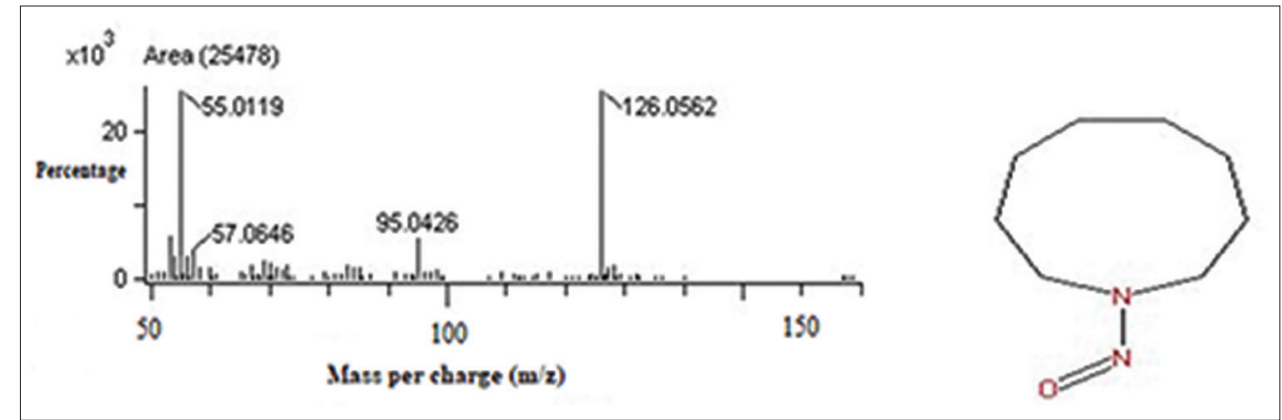

Fig. 2: Best hit and chemical structures of $1 \mathrm{H}$-azonine, octahydro-1-nitroso

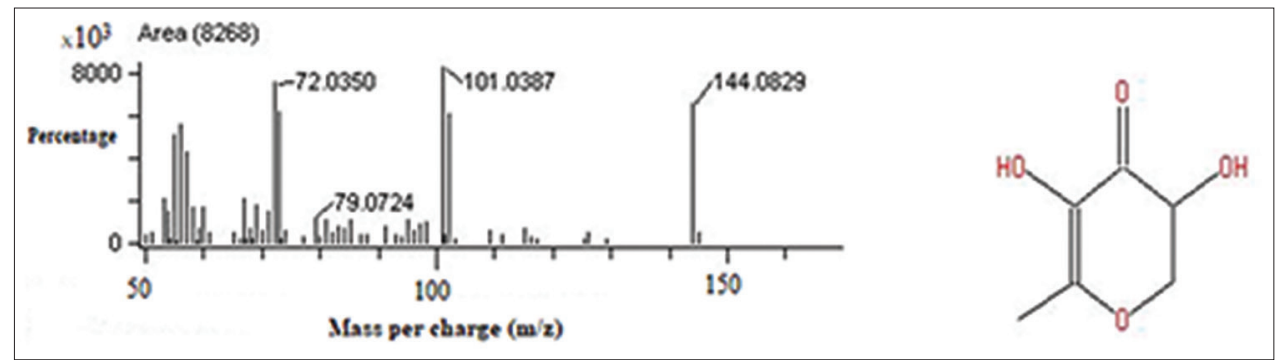

Fig. 3: Best hit and chemical structures of 4H-pyran-4-one, 2,3-dihydro-3,5-dihydroxy -6-methyl

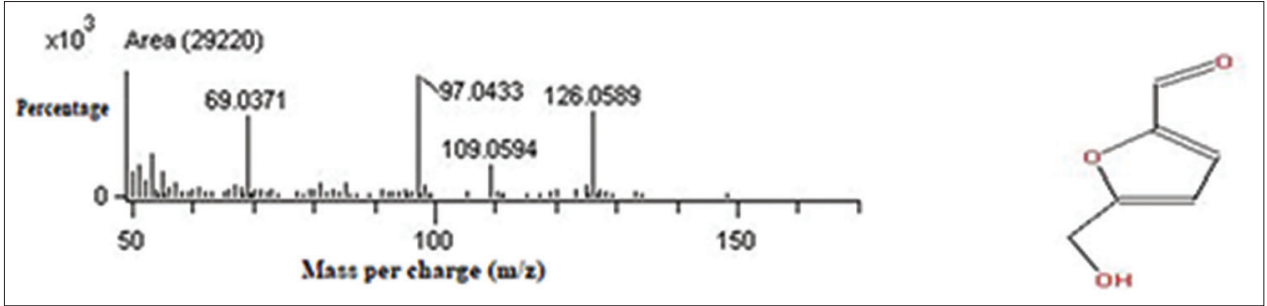

Fig. 4: Best hit and chemical structures of 2-furancarboxaldehyde, 5-[hydroxymethyl]

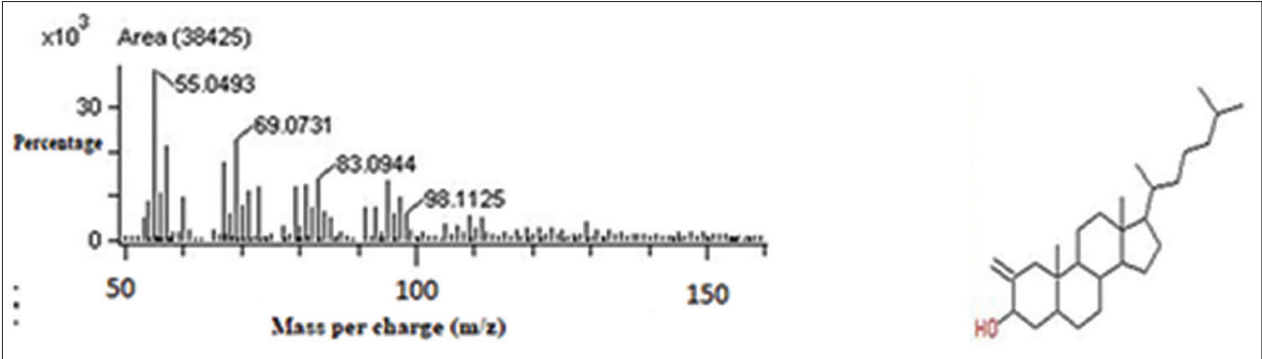

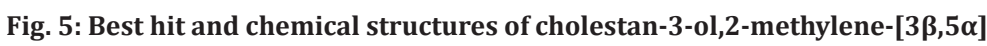




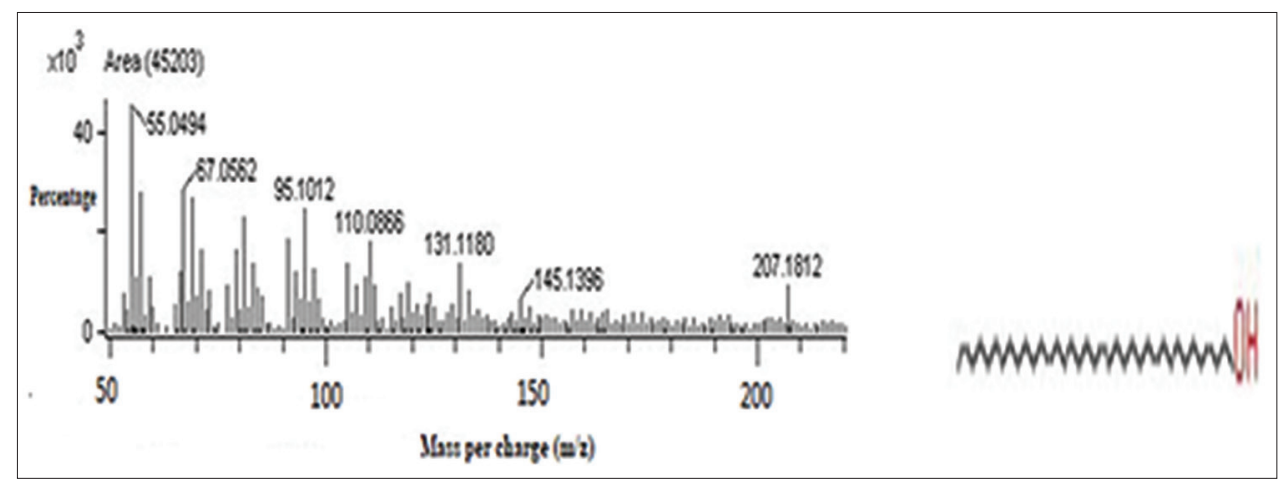

Fig. 6: Best hit and chemical structures of 1-heptatriacontanol

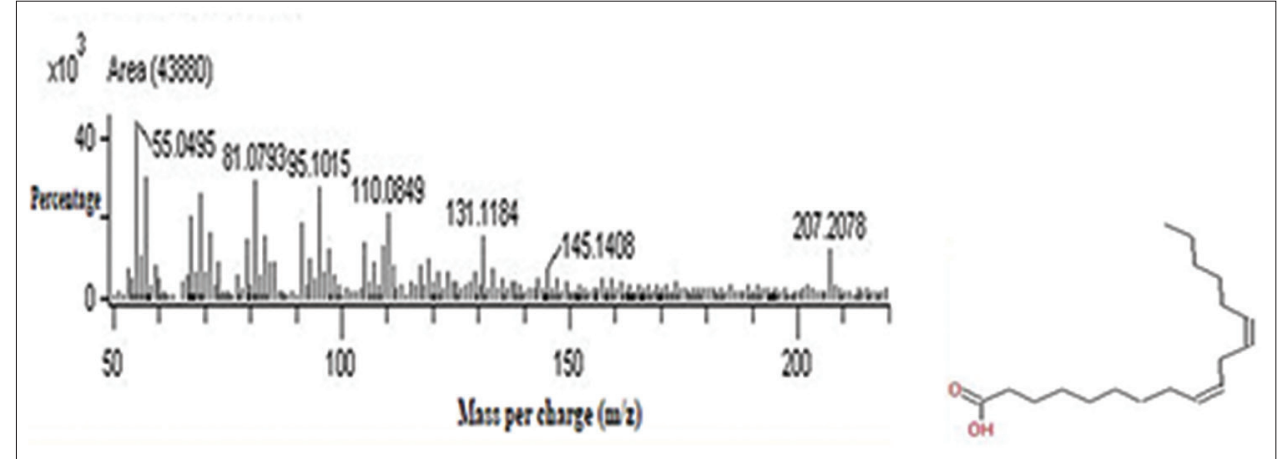

Fig. 7: Best hit and chemical structures of 9 12-octadecadienoic acids (z z)-

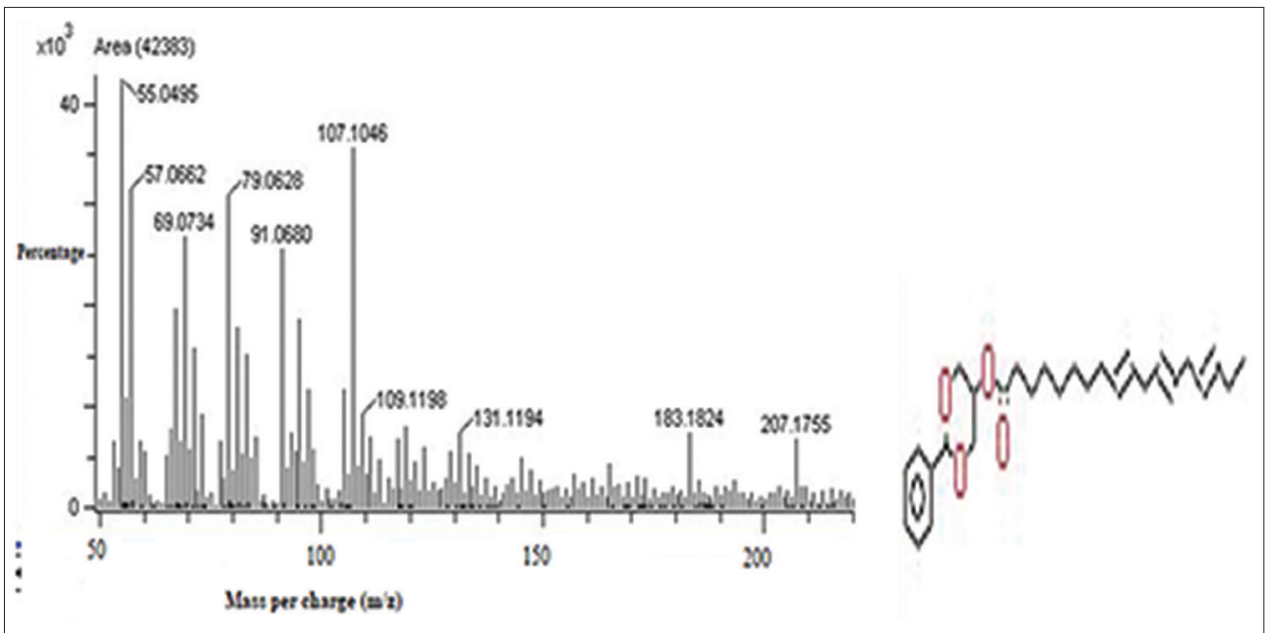

Fig. 8: Best hit and chemical structures of 9, 12, 15, octadecatrienoic acid, 2-[(trimethylsiyl] oxy]-1- [(trimethylsiyl] oxy] methyl] ethyl ester, [ZZZ]

\section{GC-MS of methanol extracts of $Z$. rhetsa ripened fruit}

GC-MS chromatogram of the methanol extract of the ripened fruit of $Z$. rhetsa showed fifteen peaks. The constituents are depicted in Figs. 9-16 and Table 2 with their RT, molecular formula, molecular weight, area, probability percentage, and important activity. Higher probability percentage was recorded in 2-furancarboxaldehyde, 5-[hydroxymethyl] (90.2\%), H-pyran4-one, 2, 3-dihydro-3, 5-dihydroxy -6-methyl (90.8), hydroquinone (64.9\%), n-hexadecanoic acid (37.5\%), and octadecanoic acid (28.2\%); remaining ones are lies in the range between $10.3 \%$ and $25.5 \%$.

In the present investigation, five compounds, namely $4 \mathrm{H}$-pyran-4one,2,3-dihydro-3,5-dihydroxy-6-methyl, 2-furancarboxaldehyde, 5-[hydroxymethyl], oleic acid, tricyclo [20.8.0.0[7,16] triacontane,1[2],7[16]-diepoxy 9,12,15, octadecatrienoic acid, and 2-[(trimethylsiyl]oxy]-1-[(trimethylsiyl]oxy] methyl] ethyl ester
[ZZZ], were observed in mature as well as the ripened fruit of Z. rhetsa.

\section{DISCUSSION}

GC-MS analysis and biological evaluation of essential oil of $z$. rhetsa were performed [36]. In this investigation, they have focused on the essential oil composition of the pericarp of $Z$. rhetsa. They have reported one of the important essential oils, i.e. hexadecanoic acid, and it is well known for its antimicrobial activity. In the present study, n-hexadecanoic acid and 9-hexadecanoic acid were recorded.

Characterization of the essential oil and fatty oil from the fruit of $Z$., rhetsa was carried out [37]. They have mentioned important fatty oils such as (Z)-9-hexadecenoic acid methyl ester, hexadecanoic acid methyl ester, (Z)- 
Table 2: The compounds identified from the methanol extract of the ripened fruit of Zanthoxylum rhetsa by GC-MS

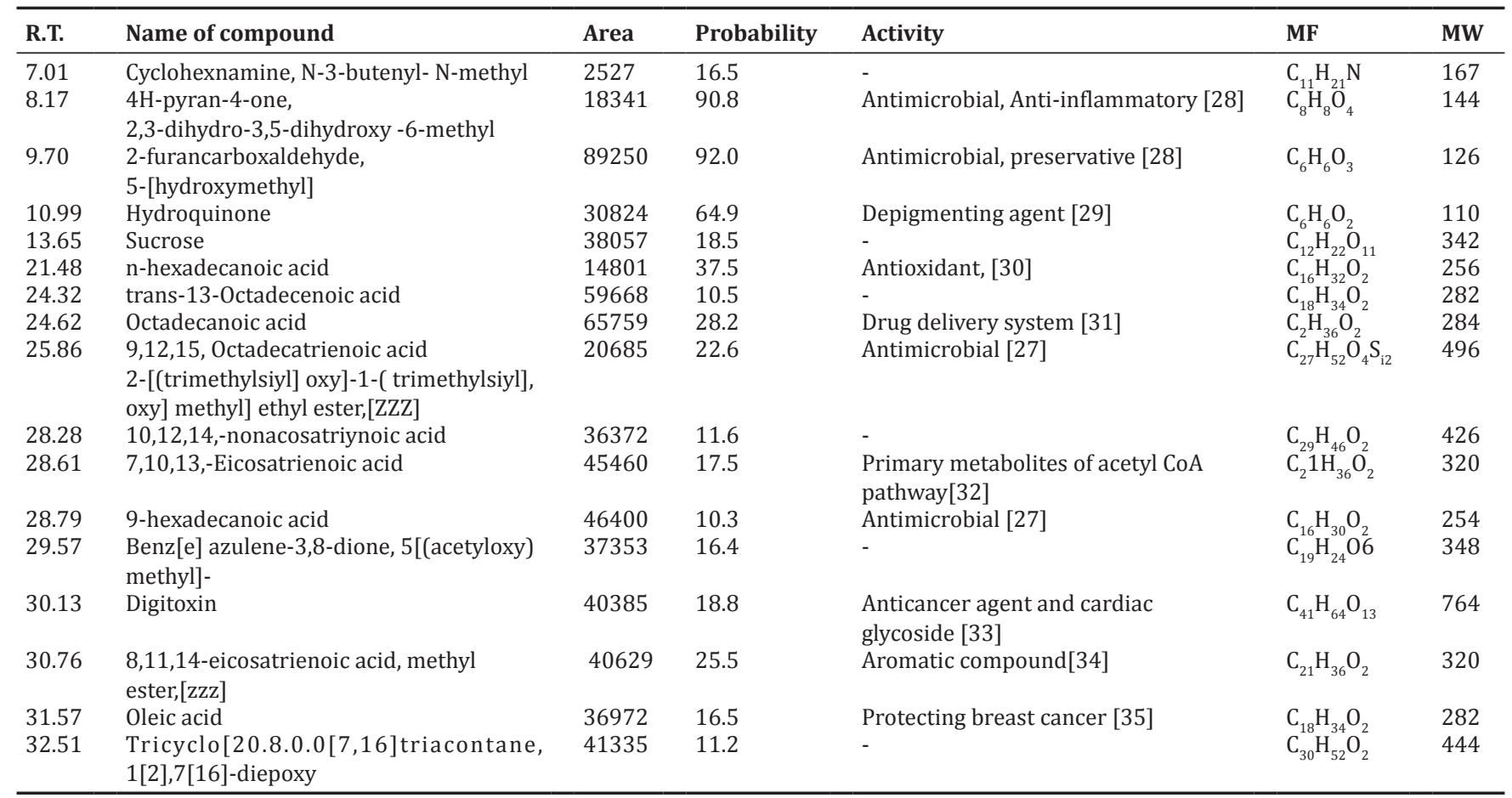

M.F: Molecular formula, M.W: Molecular weight. Probability is in percentage (\%)

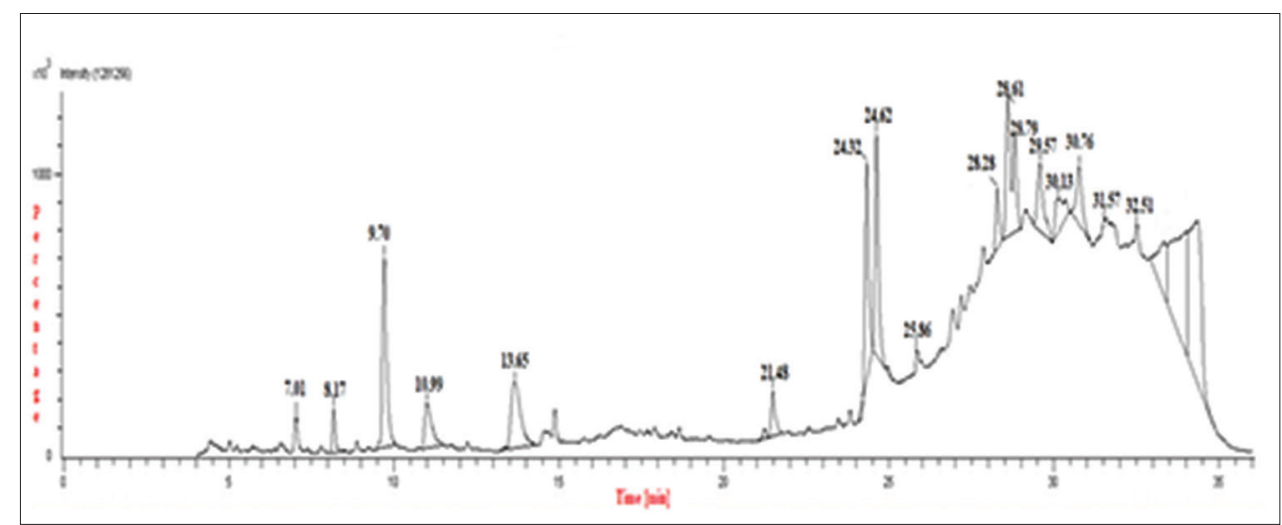

Fig. 9: Gas chromatography-mass spectrometry chromatogram of the methanol extract of Zanthoxylum rhetsa ripened fruit

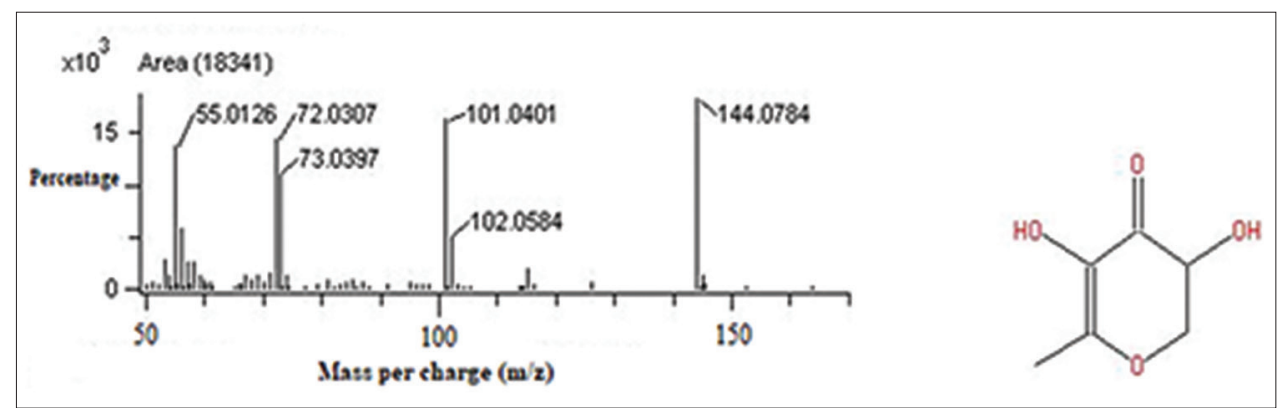

Fig. 10: Best hit and chemical structures of 4H-pyran-4-one, 2, 3-dihydro 5[hydroxymethyl]

11-octadecenoic acid methyl ester, (Z,Z), 9,12-octadecadienoic acid methyl ester,(ZZZ), 9,12,15-octadecatrienoic acid methyl ester, 11-eicosenoic acid methyl ester, and essential oil such as thujene, $\alpha$-pinene, sabinene, $\beta$-myrcene, $\beta$ - pinene, 3-career, p-cymene, limonene, ocimene, and $\gamma$ - terpinene. In the present investigation, 9,12,15, octadecatrienoic acid, 2-[(trimethylsiyl] oxy]-1-[(trimethylsiyl]oxy] methyl] ethyl ester[ZZZ], 8,11,14-eicosatrienoic acid methyl ester,[zzz], 7,10,13,-Eicosatrienoic acid methyl ester, 9 12-octadecadienoic acid (z z)-, 9,12,15-Octadecatrienoic acid, and 2-phenyl-1,3-dioxane-5-yl ester were reported.

Digitalis therapy in patients with congestive heart failure was carried out [38]. According to them, digitalis contains four important 


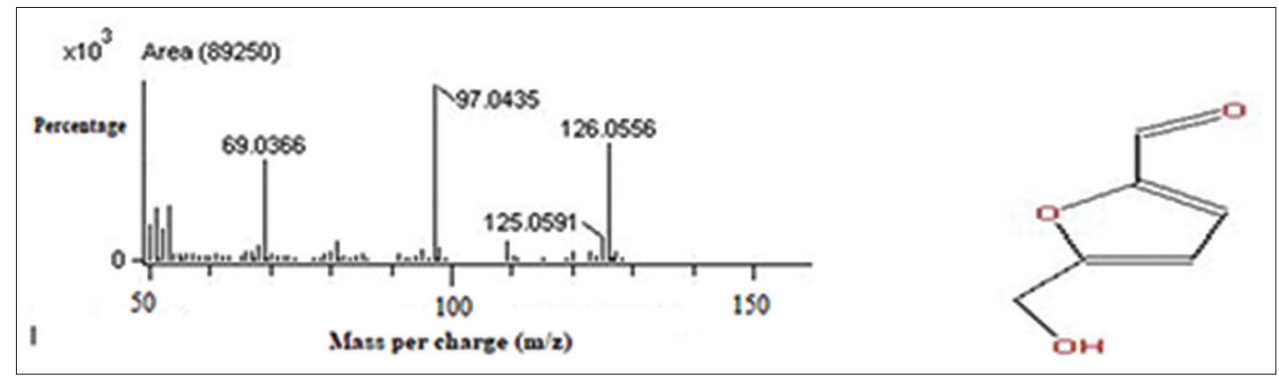

Fig. 11: Best hit and chemical structures of 2-furancarboxaldehyde, 5[hydroxymethyl]

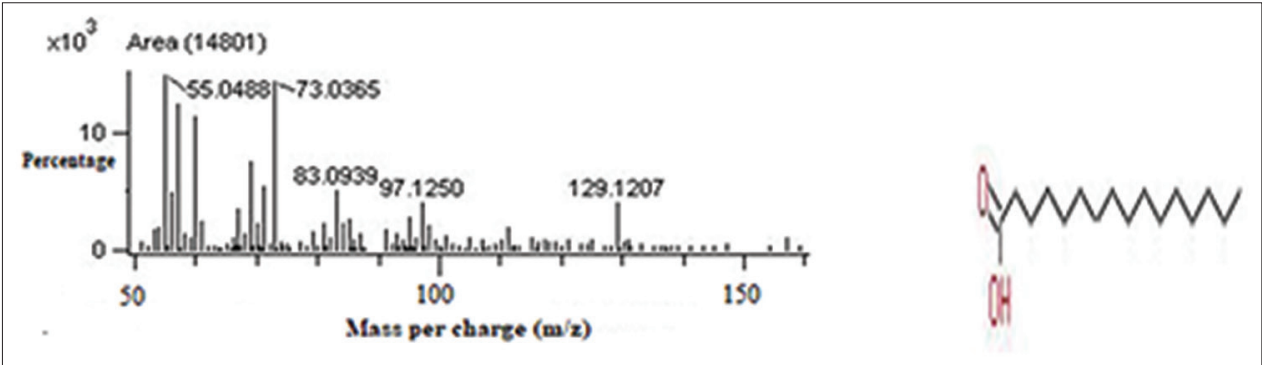

Fig. 12: Best hit and chemical structures of $\mathbf{n}$-hexadecanoic acid

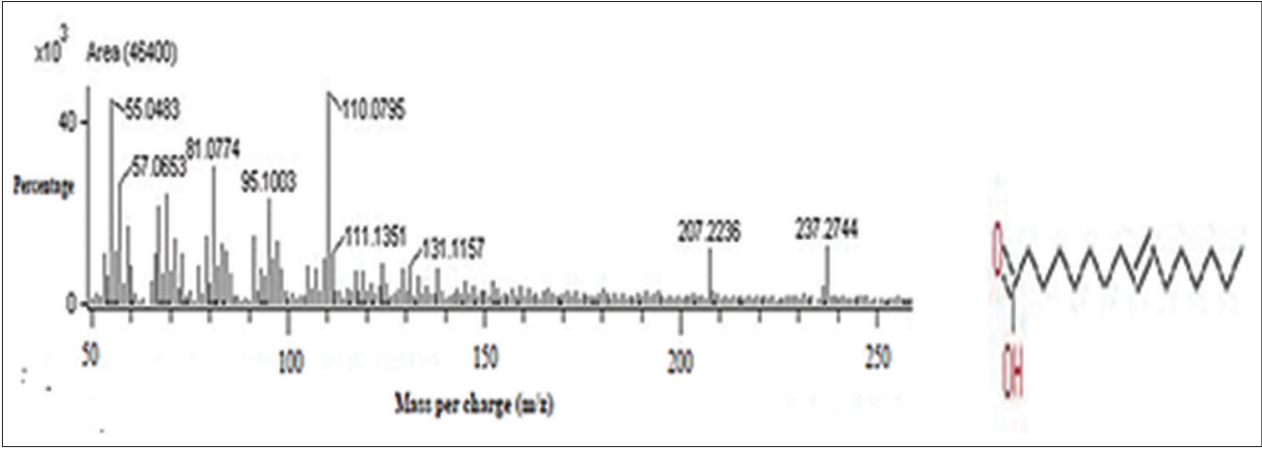

Fig. 13: Best hit and chemical structures of 9-hexadecanoic acid

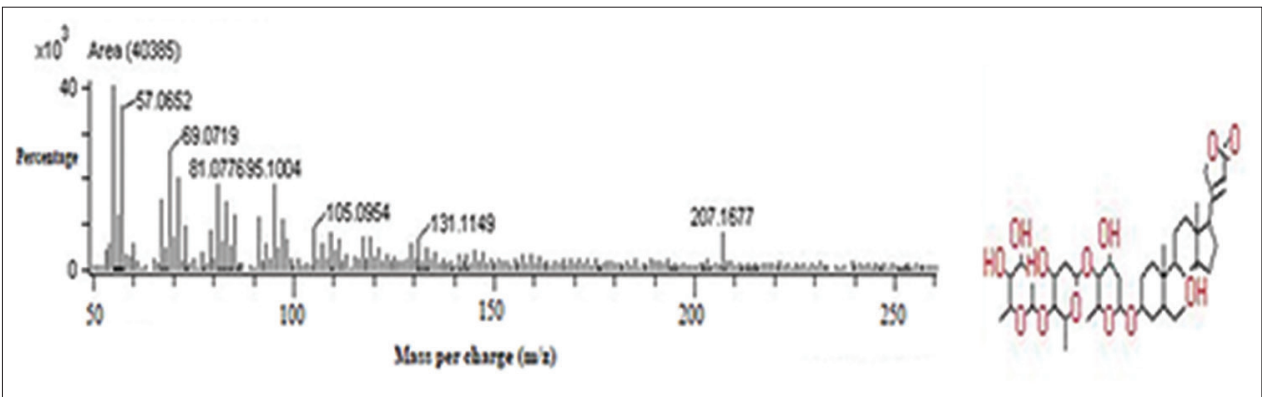

Fig. 14: Best hit and chemical structures of digitoxin

glucosides such as digitalin, digitale, digitonin, and digitoxin. The digitoxin is most powerful, extremely poisonous, and cumulative drug. The present study showed the presence of digitoxin $(18.8 \%)$ in the ripened fruit of $Z$. rhetsa.

Bioactive constituents of $Z$. rhetsa bark and its cytotoxic potential against B16-F10 melanoma cancer and normal human dermal fibroblast (HDF) cell lines were carried out [39]. They have mentioned the isolation of major volatile constituents such as tetrahydrofuran lignans (yangambin and kobusin), berberine alkaloid (columbamine), and a triterpenoid (lupeol) from the bark of $Z$. rhetsa. They tested the solvent fractions and purified compounds for their cytotoxic potential against HDF and mouse melanoma (B16-F10) cells, using the MTT assay. The chloroform fraction and kobusin exhibited a cytotoxic effect against B16-F10 melanoma cells. In the present study, digitoxin is recorded in the ripened fruit of Z. rhetsa, and it shows the anticancerous and cardiac arrest properties. Hence, in future, this plant will play a promising role in curing cancer.

GC-MS analysis of the hexane extract of Zanthoxylum armatum fruits was carried out [40]. They have recorded 36 chemical compounds. Some of them are as follows Eucalyptol, linalool, quercitron, menthoglycol, trans-pipertiol, carveole, exo-2-hydroxy-1 and 8-cineole, the aspirane, 


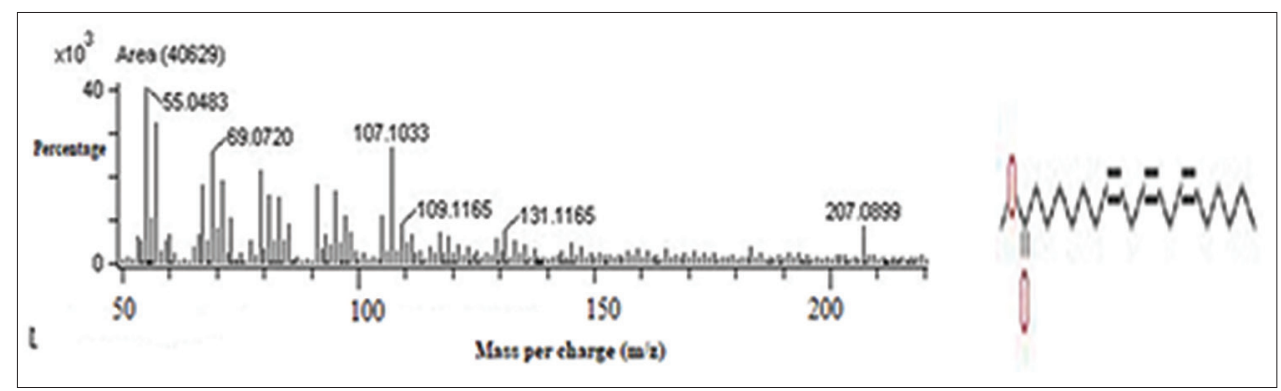

Fig. 15: Best hit and chemical structure of oleic acid

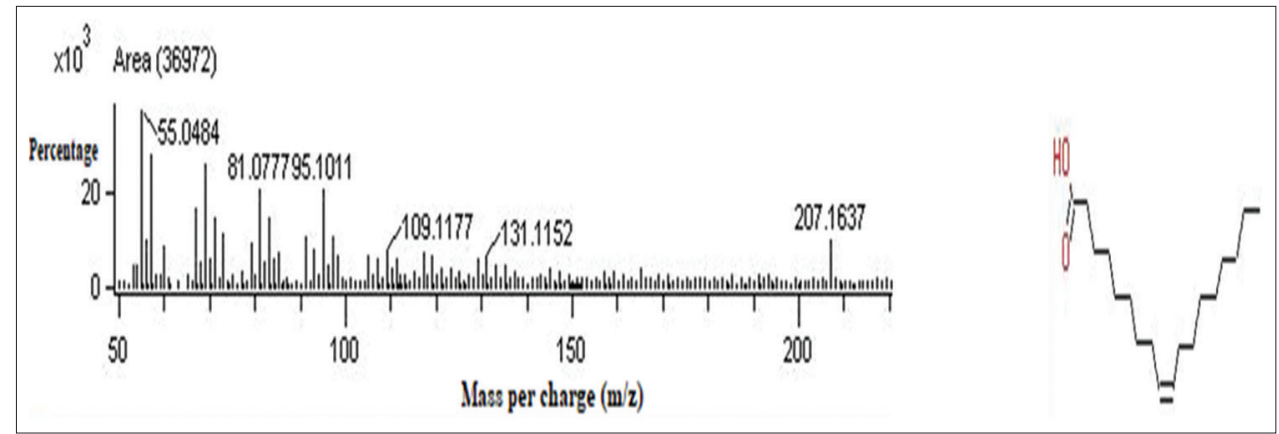

Fig. 16: Best hit and chemical structure of tricyclo $[20.8 .0 .0[7,16]$ triacontane, $1[2], 7[16]$-diepoxy

piperitone, cuminol, artemisia alcohol, caryophyllene, $\alpha$-asarone, $\beta$-asarone, 2-hydroxy cyclopentadecanone, palmitic acid, and palmitic acid methyl ester. In the present study, 32 chemical compounds were recorded in the mature and ripened fruit of $Z$. rhetsa. They have not mentioned the stage of fruit.

Estimation of some secondary metabolites from the in vitro cultures of Chlorophytum borivilianum was carried out [41]. They have mentioned 23 different types of biologically active compounds. Among these compounds, digitoxin is one of them. In the present study, digitoxin $(18.8 \%)$ is reported in the ripened fruit of $Z$. rhetsa.

\section{CONCLUSION}

In the present study, 32 compounds were present in the methanolic extract of $Z$. rhetsa fruit; among them, 15 compounds recorded in mature fruit, whereas 17 compounds in the ripened fruit. The recorded compound showed various biological activities such as anticancerous, antimicrobial, antioxidant, hypocholesterolemic, nematicide, pesticide, anti-androgenic, anti-inflammatory and anti-cardiac arrest activities. It also provides a potential source of the industrial application. One of the commercially important bioactive compounds digitoxin present in the ripened fruit which is mostly used for heart diseases. On the basis of the above results here with concluded that fruit of $Z$. rhetsa medicinally important.

\section{ACKNOWLEDGMENT}

I am thankful to the Department of Botany Shivaji University, Kolhapur, for extended support and providing necessary facilities during the tenure of this work.

\section{AUTHORS' CONTRIBUTION}

The author carried out the experiment and wrote the manuscript with support from DrV. D. Jadhav. Dr. V. D. Jadhav also supervised the manuscript.

\section{CONFLICTS OF INTEREST}

There are no conflicts of interest.

\section{REFERENCES}

1. Velayutham P, Karthi C. GC-MS profile of in vivo, in vitro and fungal elicited in vitro leaves of Hybanthus enneaspermus (L.) F. Muell. Int J Pharm Pharm Sci 2015;7:260-7.

2. Henok GA, Sahabjada, Asif J, Arshad MD, Tabarak M. Phytochemical investigation, GC-MS profile and antimicrobial activity of a medicinal plant Ruta graveolens L. from Ethiopia. Int J Pharm Pharm Sci 2017;9:29-34.

3. Seidemann J. World Spice Plants: Economic Usage. Botany, Taxonomy. U.S.: Springer-Verlag; 2005. p. 399-402.

4. Chase MW, Morton CM, Kallunki JA. phylogenetic relationships of rutaceae: A cladistic analysis of the sub families using evidence from rbcL and atpB sequence variation. Am J Bot 1999;86:1191-9.

5. Available from: https://www.gbif. orgGlobalBiodiversityInformationFacility.2010.

6. Rastogi RP, Mehrotra BN, Sinha S, Seth R. Compendium of Indian Medicinal Plants. New Delhi: Central Drug Research Institute and Publications and Information Directorate; 1990.

7. Morikawa B, Burnette R. Zanthoxylum propagation study in Northern Thailand. Plant with Purpose and Upland Holistic Development Project 2006. Available from: https://www.ngoaidmap.org/.

8. Karthikeyan AV, Sudan I. GC-MS profile of in vivo and in vitro shoots of Cleome gynandra L. Int J Pharm Pharm Sci 2017;9:21-6.

9. Singariya PP, Kumar KK, Mourya KK. Estimation of bio-activity of arial parts of Withania somnifera against the bacterial and fungal microbes. Int J Pharm Pharm Sci 2012;4:553-7.

10. Singariya PP, Kumar KK, Maurya KK. Qualitative and pharmacological examination of root extracts of Withania somnifera against human and plant pathogens. Asian J Res Chem 2012;5:733-7.

11. Singariya PP, Kumar KK, Mourya KK. Insignificant antimicrobial activities and phyto-chemical screening in different extracts of Indian ginseng. J Pharm Negat Results 2012;3:41-5.

12. Subramanian SS, Nagarajan S. Flavonoid of the seeds of Crotalaria retusa and C. striata. Curr Sci 1969;38:65-8.

13. Singariya PP, Kumar KK, Mourya KK. The absence of antibiotic activities of Cenchrus setigerus and Cenchrus ciliaris seed extract in different polar solvents. J Pharm Negat Results 2013;4:71-5.

14. Singariya PP, Kumar KK, Mourya KK. Evaluation of Indian Ginseng against different bacteria and fungi. Asia J Pharm Clin Res 2012;5:145-8

15. Singariya PP, Kumar KK, Mourya KK. Evaluation of antimicrobial activity of leaf extracts of winter cheery Withania somnifera. Int J Pharm Tech Res 2012;4:1247-53. 
16. Singariya PP, Kumar KK, Mourya KK. Screening for antimicrobial potency of methanolic extract of Indian ginseng. Int J Pharm Technol 2012; 4:4537-48.

17. Hema RS, Kumaravel SG, Sivasubramaniam C. Gas chromatographymass spectroscopic analysis of Lawsonia inermis leaves. N Y Sci J 2010;3:141-3.

18. Singariya PP, Kumar KK, Mourya KK. Isolation of new steroids and evaluation of bio-activity of Kala Dhaman grass Cenchrus setigerus. Braz Arch Biol Technol 2014;57:62-9.

19. Singariya PP, Kumar KK, Mourya KK. In-vitro studies of antimicrobial activity of crude extracts of the Indian grasses Dhaman Cenchrus ciliaris and Kaladhaman C. setigerus. Indian J Pharm Sci 2012;74:261-5.

20. Khandekar US. Extraction, characterization, and preparation of structural analog of bioactive chemicals from leaves of Echinops ecinatus plant. Minor Res Project 2016;3:1-5

21. Jyothirmayi N, Rao NM. Antibacterial activity and GC-MS analysis of ripened and unripened banana Musa paradiscia L. chakkarakeli fruit pulp extracts. Pharm Lett 2016;8:331-7.

22. Gopalakrishnan K, Udayakumar R. GC-MS analysis of phyto compounds of leaf and stem of Marsile aquadrifolia (L.) Int J Biochem Res Rev 2014;4:517-26.

23. Ibrahim IA, Hadi MY, Hameed IH. Analysis of bioactive compounds of methanolic leaves extract of Mentha pulegium using gas chromatography-mass spectrometry (GC-MS) technique. Int J Pharm Quality Ass 2017;8:174-82.

24. Karacor K, Cam M. Effects of oleic acid. Med Sci Disc 2015;2:125-32.

25. Mohammed GJ, Omran AM, Hussein HM. Antibacterial and phytochemical analysis of Piper nigrum using GCMS and FTIR. Int J Pharmacol Phytochem Res 2016;8:977-96.

26. Parthipan B, Suky MG, Mohan VR. GC-MS analysis of phytocomponents in Pleiospermium alatum (Wall. ex Wight and Arn.) Swingle, Rutaceae. J Pharmacol Phytochem 2015;4:216-22.

27. Rahman MM, Ahmad SH, Mohamed MT, Rahman MZ. Antimicrobial compounds from leaf extracts of Jatropha curcas, Psidium guajava, and Andrographis paniculata. Sci World J 2014;2014:1-8.

28. Shibula K, Velavan S. Determination of phytocomponents in methanolic extract of Annona muricata leaf using GC-MS technique. Int J Pharmacogn Phytochem Res 2015;7:1251-5.

29. Bandyopadhyay D. Tropical treatment of melasma. Indian J Dermatol 2009;54:303-9.

30. Selvarani K, Stella Bai GV. GC-MS analysis of biologically active compounds in Cayratia pedata (lam) leaf and callus extracts. Int $\mathrm{J}$ Chem 2014;2:51-6.

31. Killen BU, Corrigan OI. Factors influencing drug release from stearic acid based compacts. Int J Pharm 2001;228:189-98

32. Petkov G, Garcia G. Which are fatty acids of the green alga chlorella? Biochem Syst Ecol 2007;35:281-85.

33. Haux J. Digitoxin is a potential anticancer agent for several types of cancer. Med Hypotheses 1999;53:543-8.

34. Chen D, Zhang M. Analysis of volatile compounds in Chinese mitten crab (Eriocheir sinensis). J Food Drug Anal 2005;9:75-8

35. David TW. Oleic acid - The anti-breast cancer component in olive oil. Ass Univ J Tech 2005;9:75-8.

36. Naik RR, Shakya AK, Khalaf AN, Abuhamdah S, Oriquat GA, Anwar M. GC-MS analysis and biological evaluation of essential oil of Zanthoxylum rhetsa (Roxb.) DC pericarp. Jord J Pharm Sci 2015;8:181-93.

37. Bubpawan P, Boonphong S, Sriwattanawarunyoo C, Udeye V. Characterization of the essential oil and fatty oil from Makhwaen fruit Zanthoxylum rhetsa (Roxb.) DC. Int J Sci 2015;12:1-10.

38. Reddy BA. Digitalis therapy in patients with congestive heart failure. Int J Pharm Sci Rev Res 2010;3:90-5.

39. Santhanam RK, Ahmad S, Abas F, Ismail IS, Rukayadi Y, Akhtar MT, et al. Bioactive constituents of Zanthoxylum rhetsa bark and its cytotoxic potential against B16-F10 melanoma cancer and normal human dermal fibroblast (HDF) cell lines. Molecules 2016;21:1-13.

40. Kayat HP, Gautam SR, Jha RN. GC-MS analysis of hexane extract of Zanthoxylum armatum DC. Fruits. J Pharmacogn Phytochem 2016;5:58-62.

41. Jha A, Bansal YK. Estimation of some secondary metabolites from the in vitro cultures of Chlorophytum borivilianum sant. et. Fern. Int J Pharm Pharm Sci 2018;10:36-45. 